\title{
Steps in Developing a Public Health Surveillance System for Fathers
}

\author{
Clarissa D. Simon and Craig F. Garfield
}

In 2014, fatherhood experts from Northwestern University and reproductive health experts from the Centers for Disease Control and Prevention (CDC) Division of Reproductive Health (DRH) collaborated to conduct formative research to inform development of a public health surveillance system for fathers in the United States. This system would bridge from the Pregnancy Risk Assessment Monitoring System (PRAMS), which collects site-specific, population-based data on self-reported maternal attitudes and experiences before, during, and shortly after pregnancy. PRAMS was established in 1987 through a collaboration between CDC and 5 states and the District of Columbia (Colley et al. 1999). Over the past 30+ years, PRAMS has expanded to 47 states, the District of Columbia, New York City, and Puerto Rico, representing approximately $83 \%$ of all births in the United States (Shulman et al. 2018). PRAMS data have been used to measure progress towards achieving Healthy People 2020 objectives (Suellentrop et al. 2006) and Title V National Performance Measures (US Department of Health and Human Services 2019), such as pre-conception health care (Robbins et al. 2018) and infant sleep positioning (Hirai et al. 2019). Our goal was to develop a parallel system for new fathers to improve understanding of their health, experiences, and behaviors before, during, and after the birth of their child (Garfield et al. 2018).

\footnotetext{
C. D. Simon

Family and Child Health Innovations Program, Smith Child Health Outcomes, Research, and Evaluation Center, Ann \& Robert H. Lurie Children's Hospital, Chicago, IL, USA e-mail: csimon@luriechildrens.org

C. F. Garfield (四)

Family and Child Health Innovations Program, Smith Child Health Outcomes, Research, and Evaluation Center, Ann \& Robert H. Lurie Children's Hospital, Chicago, IL, USA

Department of Pediatrics, Northwestern University Feinberg School of Medicine, Chicago, IL, USA

e-mail: c-garfield@northwestern.edu
} 
Three main issues for conducting public health surveillance with new fathers emerged: (1) how to reach the greatest number of fathers; (2) what questions and content areas are fathers willing to answer; and, (3) what methods of data collection are most effective at reaching fathers. To address these issues we utilized a multipronged approach to inform development of a public health surveillance system for fathers: (1) reviewed the literature to identify what is known about fatherhood, including gaps in knowledge on male and family health and current national-level fatherhood surveillance data; (2) assessed feasibility of identifying fathers to participate in a national-level public health surveillance system; (3) conducted formative research to develop methodology; and (4) piloted a public health surveillance system for fathers called the Pregnancy Risk Assessment Monitoring System for Dads or "PRAMS for Dads." Our approaches are described in detail in the following section.

\section{Review of the Role of Fatherhood in Male and Family Health and Current National Surveillance Data on Young Men and Fathers}

As men increasingly play integral family and parenting roles (Bianchi et al. 2006), research on fathers' roles and contributions to families has expanded. Father involvement with their children is linked to better maternal health during pregnancy and in the postpartum period, as well as to improved health for children (Teitler 2001; Yargawa and Leonardi-Bee 2015 see also, in this volume, chapters by Kotelchuck and Yogman \& Eppel). Fathers' involvement has been associated with early prenatal care initiation and breastfeeding initiation and continuation (Teitler 2001; Hunter and Cattelona 2014), and also improved child developmental, psychological, and cognitive outcomes (Sarkadi et al. 2008; Cabrera et al. 2018).

Evidence suggests the quality of father involvement changes depending on how healthy men are; for example, depressed fathers are less likely to read to children and more likely to use corporeal punishment with their children (Ramchandani et al. 2005; Davis et al. 2011). Keeping men healthy during the preconception period (before their partner's pregnancy) and throughout their transition to fatherhood is important for improving reproductive health outcomes for fathers and their partners (Frey et al. 2008). Healthy fathers are more likely to have healthy offspring, support partners in parenting, and participate more fully in childrearing (Yogman et al. 2016). Becoming a father has been shown to influence men's health including effects on paternal mental health and physical health (Body Mass Index) (Garfield et al. 2016; see also chapter “The Impact of Father's Health on Reproductive and Infant Health and Development" by Kotelchuck in this volume). While men have become more involved with their children and within their families (Parker and Wang 2013), less is known about the transition to fatherhood as a distinct phenomenon, and how this might serve as a lever for improving men's health. An ongoing public health surveillance system at the state and national level could be used to address the gaps 
in knowledge around the transition to fatherhood and to inform efforts to improve the health and well-being of fathers, mothers, and their families.

A number of family-centered public health surveillance systems have led the way towards better understanding the health of men and fatherhood in the United States. The National Health Interview Survey (NHIS), which has monitored national trends in illness and disability since 1957 (Schiller et al. 2012), and the Behavioral Risk Factor Surveillance System (BRFSS), which has collected state-specific data on health-related risk behaviors since 1984 (Balluz et al. 2008), both provide information on health status and use of health services by women and men. Neither of these surveys, however, directly examine the transition to fatherhood or are specific to fathers. Since 1973, the National Survey of Family Growth (NSFG) has provided information on the health status and behaviors of reproductive-aged women through periodic surveys (Groves et al. 2009). Starting in 2002, a parallel survey for men (ages 15-44) was initiated to collect data on attitudes and experiences around marriage, childrearing, sexual behaviors, and contraceptive use (Marcell et al. 2016).

Currently, data on paternal involvement is mainly limited to the Fragile Families and Child Wellbeing Study (FFCWS) ${ }^{1}$ and the Early Childhood Longitudinal Study of Birth (ECLS). ${ }^{2}$ The FFCWS is a birth-cohort study of children living in major U.S cities, first interviewing fathers shortly after the birth of a child and an additional interview at the hospital or following baby's hospital discharge. The FFCWS collects important data on father involvement over time directly from both resident and non-resident fathers, including time with children, financial support for unmarried parents (Carlson and McLanahan 2010). The ECLS-B (Birth Cohort) is a nationally representative cohort study with fathers first interviewed when children were 9 months old, and also including measures of father involvement such as infant engagement and identification with the fathering role (Planalp and Braungart-Rieker 2016). Early Head Start, a program providing family-centered services for low-income families with children up to age $3,{ }^{3}$ developed fatherhood demonstration projects ${ }^{4}$ evaluations that showed incredible success of father-centered programming to more fully involve fathers in the lives of their young children (Burwick et al. 2004). Aside from the aforementioned, there is currently no public health surveillance system collecting site-specific and population-based datafocused on the transition to fatherhood during the perinatal period.

\footnotetext{
${ }^{1}$ The FFCWS is a joint effort from Princeton University's Center for Research on Child Wellbeing and the Columbia Population Research Center.

${ }^{2}$ The ECLS is sponsored primarily by the U.S. Department of Education, National Center for Education Statistics.

${ }^{3}$ Early Head Start is funded by the Administration for Children and Families (ACF), a division of the Department of Health \& Human Services.

${ }^{4}$ The 21 Early Head Start fatherhood demonstration projects were funded by the ACF and the Office of Child Support Enforcement.
} 


\section{Assessing the Feasibility of Sampling Fathers for a National-Level Public Health Surveillance System}

The first step in developing a public health surveillance system for fathers was to determine the feasibility of sampling fathers to participate. Our aim was to determine whether it would be feasible to adapt the existing PRAMS sampling methodology for a public health surveillance system for fathers.

\subsection{Use of Birth Records}

PRAMS sites randomly selects new mothers using birth certificate data, to participate in the PRAMS survey. The standard certificate of live birth in the United States has 58 data fields, most of which relate to the mother (including her contact information) and infant. Only seven data points on the standard U.S. birth certificate relate to fathers, and these are all reported second hand by mothers, including the father's name and his date of birth (Centers for Disease Control and Prevention 2016). Data collected on births at the state level are entered into the Electronic Birth Registration System (EBRS). No separate contact information for the father, apart from what is reported by mothers, is included on a standard U.S. birth certificate, although the address listed will match the father if he lives with the mother. Married couples are assumed to live together, and non-married couples are encouraged to complete a separate Acknowledgment of Paternity (AOP, alternatively called the Voluntary Acknowledgement of Paternity) form in order for the father's information to be included on the birth certificate. More information on the AOP is provided below.

\subsection{State input}

State health department representatives from Connecticut, Florida, Illinois, Louisiana, Michigan, Minnesota, Oklahoma, Utah, and Washington provided information about birth certificate data collection and information available related to fathers. This information sharing process highlighted challenges in collecting new father information nationally. Table 1 displays the availability of this information from the following three sources: (1) typical, standard U.S. birth certificate, (2) paternity form information from Illinois and (3) paternity form information from Georgia, the first state to pilot PRAMS for Dads. Father data from these sources varies widely in completeness and quality, both between and within states, since each state has its own process and policies. Further, while the birth certificate lists the mother's address, an unmarried father who does not live with the mother has no separate address listing, unless the AOP form is completed. 
Table 1 Availability of institutional parental data from birth certificates and acknowledgement of paternity forms from two sample states

\begin{tabular}{|c|c|c|c|}
\hline & $\begin{array}{l}\text { Standard } \\
\text { U.S. Birth } \\
\text { Certificate }\end{array}$ & $\begin{array}{l}\text { Illinois Voluntary } \\
\text { Acknowledgment of } \\
\text { Paternity }\end{array}$ & $\begin{array}{l}\text { Georgia Paternity } \\
\text { Acknowledgment } \\
\text { Form }\end{array}$ \\
\hline \multicolumn{4}{|c|}{ Mother demographic information } \\
\hline Name & Yes & Yes & Yes \\
\hline Name prior to marriage & Yes & Yes & No \\
\hline Address & Yes & Yes & Yes \\
\hline DOB & Yes & Yes & Yes \\
\hline Place of birth & Yes & Yes & Yes \\
\hline Mailing address & Yes & No & No \\
\hline Marital status & Yes & No & No \\
\hline $\begin{array}{l}\text { Married to person other } \\
\text { than father listed }\end{array}$ & No & Yes & No \\
\hline Social security number & Yes & Yes & Yes \\
\hline Education & Yes & No & No \\
\hline Race/ethnicity & Yes & No & No \\
\hline Phone number & No & Yes & No \\
\hline Employer & No & No & Yes \\
\hline Employer address & No & No & Yes \\
\hline \multicolumn{4}{|c|}{ Father demographic information } \\
\hline Name & Yes & Yes & Yes \\
\hline Address & No & Yes & Yes \\
\hline DOB & Yes & Yes & Yes \\
\hline Place of birth & Yes & Yes & Yes \\
\hline Social security number & Yes & Yes & Yes \\
\hline Education & Yes & No & No \\
\hline Race/ethnicity & Yes & No & No \\
\hline Phone number & No & Yes & No \\
\hline $\begin{array}{l}\text { Father acknowledges that } \\
\text { he is the biological father }\end{array}$ & No & Yes & Yes \\
\hline Employer & No & No & Yes \\
\hline Employer address & No & No & Yes \\
\hline
\end{tabular}

Although this information is not required on the standard U.S. birth certificate, phone number availability for fathers is important for reaching fathers directly, rather than indirectly using mother demographic information. Furthermore, while Illinois refers to this form as a "Voluntary Acknowledgment of Paternity" form, Georgia has a "Paternity Acknowledgement Form." AOP form completeness varies due to factors such as father being absent at the hospital where most AOPs are signed since both the mother and father must sign the AOP form, either the mother or father not wanting the AOP signed, and uncertainty about biological parentage (Osborne and Dillon 2014). 
Data collected on the AOP — if it is indeed of high quality — may allow fatherhood researchers to reach unmarried U.S. fathers who do not live with their infant's mother. Since $40 \%$ of births in the U.S. are to unmarried mothers, gathering data on this large group of fathers is important (Martin et al. 2019). Unmarried fathers may be different than married fathers, including in their fatherhood experiences and how they may impact mothers and babies (Carlson and McLanahan 2010).

In summary, it was determined that PRAMS methods for sampling participants could be adapted to identify fathers to participate in a public health surveillance system for fathers. The majority of fathers and at least partial contact information could be identified using the birth certificate for fathers who were either married or were unmarried and an AOP had been completed in the hospital.

\section{Formative Research to Develop Methodology}

To assess the willingness of men to participate in a PRAMS-like survey, Northwestern University conducted a short survey with two groups: (1) men who were expecting a baby in the next 6 months ("expectant fathers"), and (2) fathers whose babies were born in the last year ("new fathers"). Expectant fathers were recruited from a fatherhood course at a large, urban birthing hospital with over 13,000 deliveries per year. During a one-time evening course held bi-monthly over an 8 month period, men were invited to complete a short one-page survey about their willingness to answer questions on a variety of topics related to their experience as fathers including, physical health, access to health care, mental health, pregnancy intendedness, partner support, involvement in childrearing, breastfeeding, and vaccines.

New fathers were recruited through a large, urban, federally qualified health center (FQHC) organization serving communities with high rates of poverty and poor health outcomes on Chicago's south and west sides. The FQHC provides preventive and primary health care, with a goal to address significant health challenges, including lack of access and variable levels of health literacy. Ninety-six percent of the FQHC patients live below $200 \%$ of the Federal Poverty Level. FQHC staff invited clients who were fathers with babies less than a year old to complete the survey. The survey for new fathers was similar to the expectant father survey, with some modifications since these were current, not prospective parents. The survey addressed willingness to answer questions about new fatherhood, demographics, and contact preferences for a prospective survey.

Below are the survey results for both groups: 


\subsection{Expectant Father and FQHC New Father Demographics}

Men in the expectant father classes $(\mathrm{n}=57)$ were primarily in their 30 s $(74 \%)$, with equal amounts of fathers in their 20s and 40s. These fathers were mostly married $(84 \%)$ or cohabiting $(12 \%)$. The FQHC new fathers $(n=36)$ were younger, with $63 \%$ in their 20 s and $16 \%$ between 32 and 37 . These fathers were also much less likely to be married, with only $35 \%$ married and $27 \%$ cohabiting.

Mode of contact. To find out how best to reach fathers, men in both groups were asked "Which of the following methods of contact is acceptable to you?" Among expectant fathers, nearly half preferred contact within 3 months of their infant's birth via either email (34\%), text messaging with a link (24\%), phone/cell call $(24 \%)$, or postal mail (15\%). In contrast, FQHC new fathers selected phone (41\%) over mail $(31 \%)$, texting with a link $(16 \%)$ or email $(10 \%)$. Overall, men in both groups preferred either phone contact or email, with texting a close third preferred mode of contact. See Fig. 1.

Time of contact. Men were asked "What is the best time after the birth of your baby to contact you for a survey about becoming a father?" Most of the fathers in both groups chose the early prenatal period as the best time to be contacted for a study on fatherhood. Expectant fathers overwhelmingly chose either the 1-3 month (47\%) or 3-6 month (29\%) postnatal time period as the preferred time to be reached for a survey, while new fathers also chose the 1-3 month $(35 \%)$ and 3-6 month (22\%) postnatal time period. See Fig. 2.

Interest in answering questions. Men in both groups were largely willing to answer questions on a variety of topics (75-85\% overall), although there was some variability in topics, particularly among the FQHC new fathers. One of the major differences was a high level of willingness to answer health access questions, but a lower willingness to answer questions about breastfeeding. Some variability was evident around the importance of these individual topics, as seen in Fig. 3.



Expectant Fathers ( $n=57) \quad$ FQHC New Fathers $(n=36)$

Fig. 1 Preferred mode of contact among expectant and new fathers 


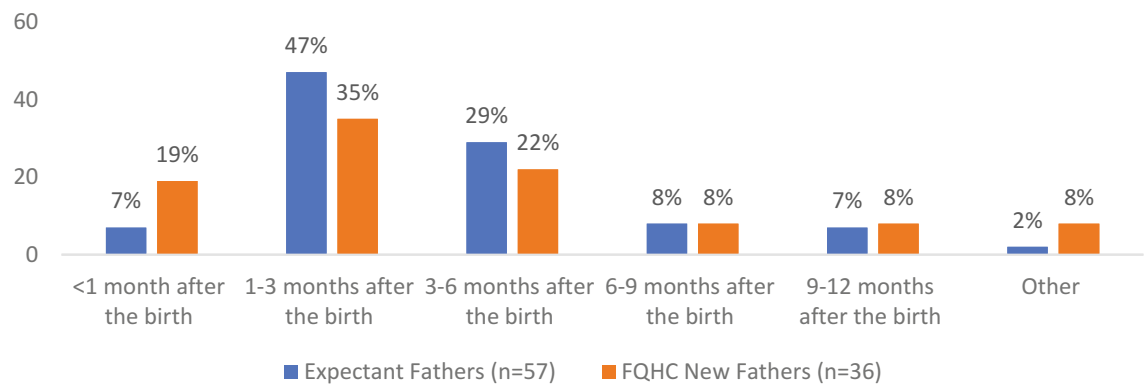

Fig. 2 Time of contact to complete a survey about becoming a father among expectant and new fathers

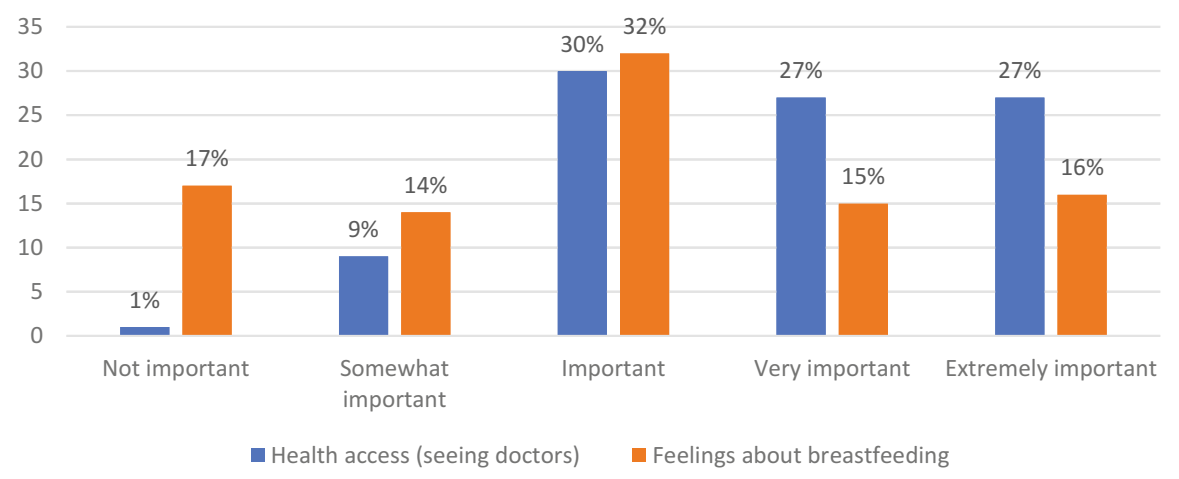

Fig. 3 Importance of health access and breastfeeding questions

Further, while all fathers answered questions about the importance of individual topics $(\mathrm{N}=93)$, five fathers did not report whether they would be willing to answer questions on these topics.

In summary, survey data from this sample of expectant and new fathers revealed high levels of willingness to answer questions on new fatherhood, a preference for contact in the early post-natal period, with mixed preferences for mode of survey contact.

\section{Focus Groups with New Parents}

To explore in more depth and in their own voices, focus groups were conducted with current fathers and mothers at the FQHC to examine their experiences as men and women becoming parents. In particular, we asked how the logistics of a survey for 
fathers in the newborn period might be received by mothers as well as fathers. Two groups of mothers (total of eight mothers) and one group of fathers (five fathers) attended the focus groups with researchers to talk about parenting and father involvement. The parents described strong commitment to their families and children, with fatherhood reported as a joyful event by fathers.

Parents reported a number of barriers to completing a survey, and concerns about financial and employment responsibilities. Mothers with male partners who do not live with them (non-cohabiting) suggested that email is best for fathers due to frequent moves. As emails generally do not change, contacting men by email may be an effective way to reach men who move often. Mothers with residential partners supported the use of postal mail for the survey. While fathers report a willingness to be contacted via email or phone, they preferred phone to email or text for a survey.

Parents highlighted that the survey should promote the fathers' role in his child's life, an approach that focuses on health promotion, and the inclusion of incentives that were sports themed or baby-themed. Although such incentives were not included in the current pilot, to help streamline initial field efforts, we hope to tailor incentives for fathers in the future. They also suggested emphasizing the importance of fathers, including the rights of fathers and value of involvement with their children. Both mothers and fathers reported that fathers can be contacted indirectly through mothers using a "mothers-as-gatekeepers" approach. They reported that this would be an effective approach if parents have a good relationship, something both parents mention could be in flux. Nonetheless, overall, fathers and mothers both affirmed their willingness to complete surveys related to their child's wellbeing (fathers) or to make sure the survey was given to the fathers (in the case of mothers).

In summary, focus groups with new mothers and fathers provided data to inform best practices for survey completion, recruitment, and questionnaires, including surfacing some potential barriers for the PRAMS for DADS survey. Fathers reported willingness to answer a variety of questions and interest in providing their "father's voice" to a survey of new parents. Similar to the survey results, a flexible multimethod contact approach may be best for reaching new fathers. A number of barriers to reaching new fathers emerged including moving to a new home (transience), a poor co-parenting relationship, and intensive work responsibilities.

\section{Collecting Father Data: Methodological Findings and Recommendations}

Based on the above formative work, we present five key findings for reaching fathers in the perinatal period:

(a) Pilot multiple approaches: Fatherhood researchers may reach more fathers through a variety of approaches including mail, email, text and phone contact. Some of these approaches may have different responses rates depending on factors such as whether the father lives with his infant or the current quality of 
the relationship with the baby's mother. Fathers also have different preferences for completing a survey using mail or by entering information on-line. Fathers who move frequently may be easier to reach using email and texting, while others may prefer traditional paper surveys sent through snail mail.

(b) Contact multiple times: Fathers may be more difficult to contact than mothers, so the number of times expected to reach new fathers should be at minimum assumed the same as that required for new mothers. Contact may be especially challenging for unmarried fathers and those who do not live with their children, since the mailing address and phone number listed on the birth certificate may not work for these fathers or even be available at all. If mothers are asked for father's information, they may be less likely to provide or have father information if they don't live with the father. Focus groups with new mothers and fathers also suggested that some fathers may move frequently, so resources may be needed to not only contact fathers more often, but also to obtain more current addresses and phone numbers.

(c) Provide adequate rewards and/or incentives: Father participants should receive similar incentives to those that mother participants receive; however, given that men can be difficult to enroll in research studies, additional or different incentives may be needed (Patel et al. 2003). Some of these options include additional gift cards for completion by a certain date or using an approach that requires less staff time, such as completing the survey online. Other non-monetary incentives like celebrity or sports star endorsements may also help increase response rates for fathers.

(d) Make special efforts to enroll hard-to-reach fathers: Some groups of fathers will likely be difficult to reach, such as those who live apart from their children or those who move frequently. Additional efforts to reach these fathers, such as increasing the number of contacts or higher value incentives may needed to ensure representativeness of the data. Otherwise, research on fatherhood may be heavily biased toward fathers who are easy-to-reach. Certain groups of fathers, such as incarcerated, adoptive, surrogate, social, and uninvolved fathers will already be lost to studies that utilize birth certificates for enrollment, so it is necessary to focus efforts and provide additional resources to increase response rates for the most difficult to reach fathers.

(e) Include a variety of survey topics, ideally in parallel to those asked of mothers. To provide both mother and father perspectives on parenting within the same family, questions domains should be similar where relevant, in addition to fatherhood-centered domains to provide the unique father perspective. These topics could include: (1) demographic questions such as relationship status and employment; (2) health-related questions such as birth control use, safe sleep practices and health care access/usage; and (3) father-specific questions such as father involvement, feelings about breastfeeding, and family leave.

(f) Carefully weigh whether to reach fathers directly or indirectly: We identified two sampling approaches to reaching fathers, which are displayed in Fig. 4. 

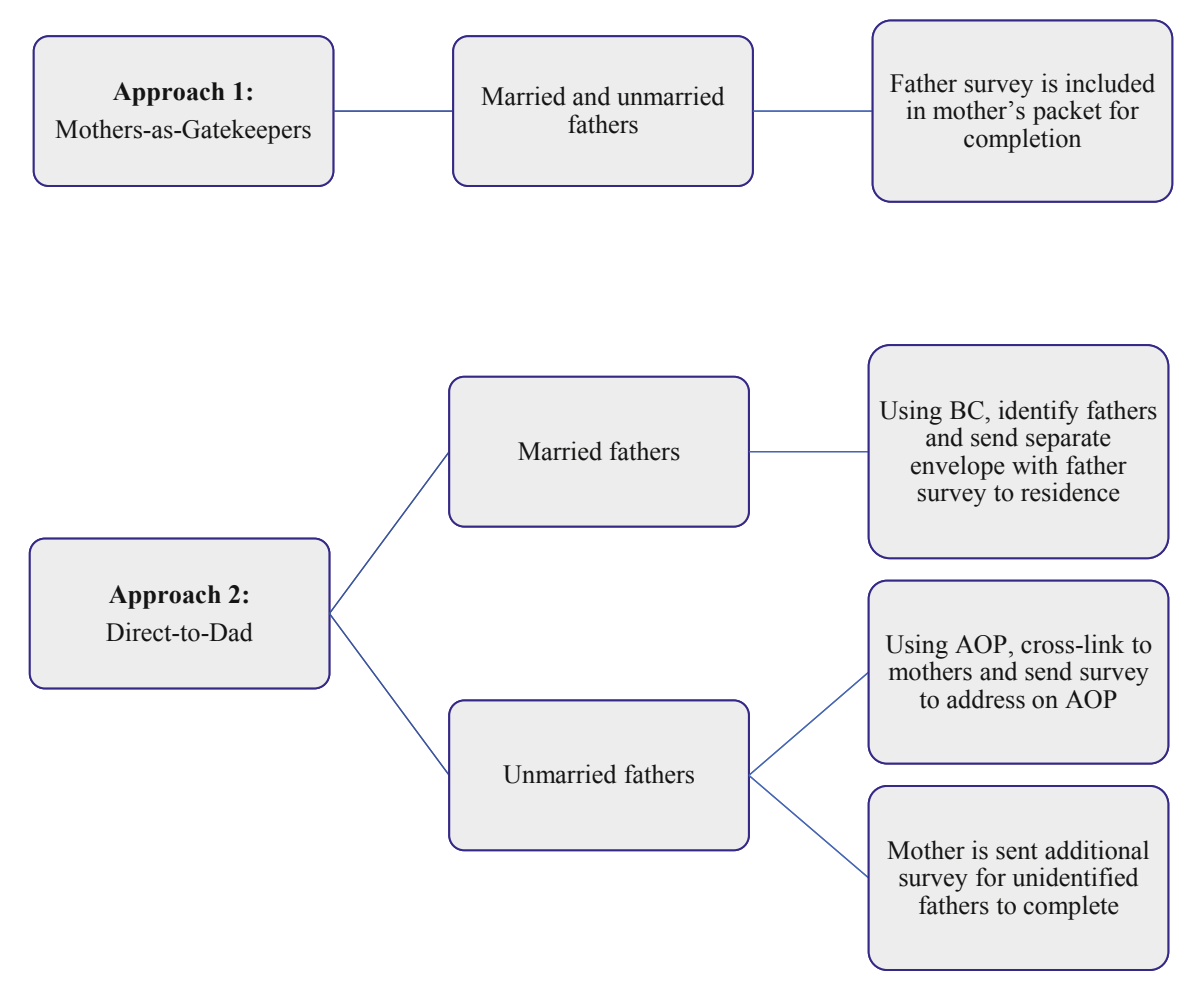

$* \mathrm{BC}=$ Birth Certificate; AOP $=$ Acknowledgement of Paternity

Fig. 4 Two approaches to reach fathers after the birth of their child. $B C$ birth certificate, $A O P$ acknowledgement of paternity

- The first approach, "Mothers-as-Gatekeepers," requires including a separate survey for fathers in the mother's survey envelope. This approach is less time and cost intensive but reaches fathers indirectly. Two assumptions are implicit: (1) that the new mother will provide the survey to the father, and (2) that the father will elect to participate. This may introduce bias toward responses of those fathers actively involved with mother and infant, particularly for fathers who do not live with their children.

- The second approach, "Direct-to-Dads," requires contacting fathers directly without requiring involvement from the mother. This approach would require additional effort and resources to identify new fathers, as the address listed for mothers on the birth certificate may not necessarily be that of fathers. While married fathers can be reached directly through the address listed on the birth certificate, unmarried fathers would be reached through the information collected on the AOP form, if available, or by sending mothers an additional survey under separate cover. With $40 \%$ of births in the U.S. to unmarried 
couples, this approach may capture more unmarried fathers, both cohabiting (living with their children) and non-cohabiting (living apart from their children). This approach considers fathers as parents and research participants apart from mothers, as it does not rely on the need for mothers to contact or approach fathers. In other words, the "Direct-to-Dads" approach allows for independent contact of fathers without using the mother as a gatekeeper of the survey.

Figure 4 below illustrates the two main approaches to reaching new fathers:

1. Approach 1 is the "Mothers-as-Gatekeepers" approach in which fathers are contacted through mothers.

2. Approach 2 is the "Direct-to-Dads" approach in which fathers are contacted directly.

Approach 1 and 2 will both reach married and unmarried fathers when an AOP was completed in the hospital. The advantages of these approaches include the ability for the data collected to be merged into already-existing vital records data and maternal contact information currently available in mother surveys. This approach also could yield interesting comparisons between mothers and fathers on particular topics, where both parents choose to participate.

\section{Piloting a Public Health Surveillance System for Fathers: PRAMS for Dads}

In October 2018 we put these findings into the field with a pilot study of PRAMS for Dads. Working with the Georgia Department of Public Health (GDPH), monthly samples of new mothers using recent birth certificates were drawn, from which fathers were identified and contacted. As with the maternal PRAMS protocol, fathers are contacted first by mail, initially with a pre-letter, then with three mailed surveys, and a "tickler" reminder mailer (Shulman et al. 2018). After this mail phase, participants move into phone phase and are contacted by phone to complete the survey. Unlike the maternal PRAMS protocol, the pre-letter includes a link to complete the survey electronically, and the three mailed surveys have the electronic link as well. A shortened URL link was created for inclusion in the letters to ease use of electronic completion. Figure 5 shows the monthly operations employed in the PRAMS for Dads pilot study.

In the pilot survey, fathers were asked a total of 71 questions, including domains such as health care access and usage, contraceptive use, cigarette and alcohol use, safe sleep practices, work leave, and father involvement. A specific section questions relevant for non-residential fathers included questions such as time spent with babies and material contributions. Questions were derived mainly from PRAMS, Fragile 


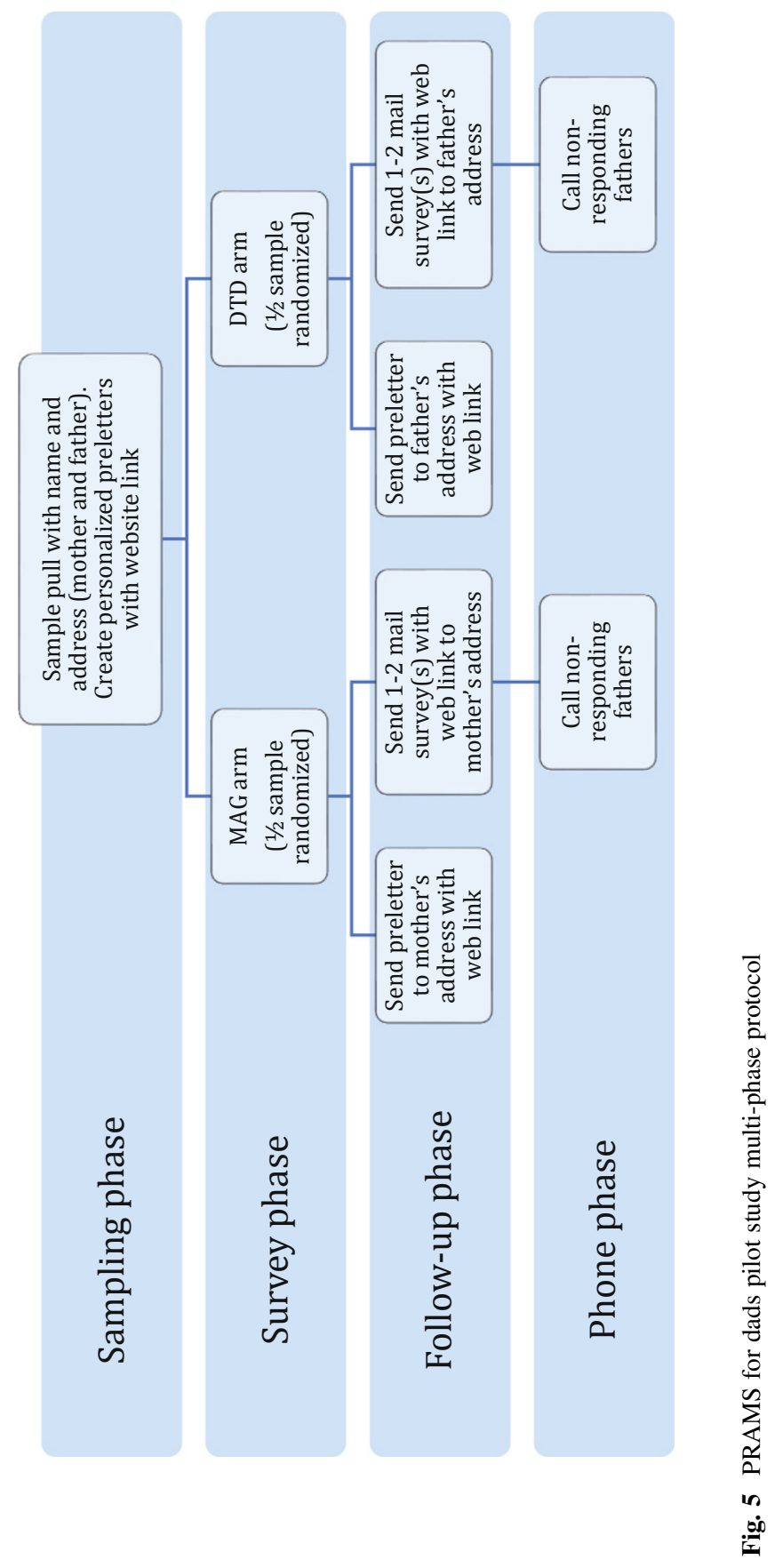


Families and Child Wellbeing Study, and the National Survey of Family Growth. Surveys were available in both English and Spanish.

Sampled fathers were randomized such that half of the fathers were contacted using Approach 1, the "Mothers-as-Gatekeepers" or MAG approach as shown above. For these fathers, surveys were sent to the mother's address listed on the birth certificate. The PRAMS for Dads survey was included in the packet mothers were asked to complete for the larger PRAMS study. Phone contacts were also made through the mother's contact information. The second half of the fathers were randomized and contacted using Approach 2, the "Direct-to-Dads" (DTD) approach. These fathers were sent their own blue envelope with a survey included, and attempts were made to find additional contact information specifically for fathers. Fathers are therefore considered independently of mothers as part of the study.

As of early 2020, we are currently in the field collecting data for the PRAMS for Dads pilot. Eventually, results from this pilot study will allow us to compare completion rates by the MAG and DTD approaches as well as the three survey completion options (e.g., mail, electronic, and phone). Best methods, as measured by highest response rates, may then be used to "scale up" the project, moving PRAMS for Dads into multiple states across the country and providing valuable data on the public health and behaviors of new fathers. Researchers and clinicians should continue to focus on the importance of hearing the voices of new fathers, both to better understand families and to promote men's health. Data devoted to the fatherhood experience is sorely needed, and PRAMS for Dads aims to help meet that need (Garfield et al. 2018).

\section{Collecting New Father Data: Overall Findings}

Based on our cumulative findings from our formative research, information gathered, and pilot study, we present five overall key findings and recommendations:

Fathers are involved and want their voices heard.

Our findings suggest that fathers want to participate in research aimed at better understanding the needs and experiences of new fathers and how to help their baby. Participation in survey research was considered by our focus group fathers a valid use of time, particularly as it relates to pathways towards helping children. With limited information on the transition to fatherhood from fathers themselves, our formative research supports that there interest in participation from fathers. We hope other researchers and clinicians pursue the challenging field of new fatherhood research, with an aim to better understand and support fathers, mothers, children, and families.

Make extra efforts to reach both fathers who live with their children (cohabiting) and fathers who live apart from their children (non-cohabiting)

In order to properly represent both sets of fathers, fatherhood research must be able to reach both groups effectively. Non-cohabiting fathers represent a large minority of fathers and less is known about how these fathers influence their 
children, in part because they are more difficult to contact. They are, however, an important group, underserved and disadvantaged, compared to fathers who live with their children and consequently their offspring may be at higher risk for poor outcomes. Since cohabiting fathers will likely be easier to reach, additional efforts must be made to reach non-cohabiting fathers.

Use acknowledgment of paternity (AOP) forms to reach more unmarried and non-cohabiting fathers, which are supplementary forms completed by unmarried fathers around the time of the birth of a child.

Utilizing address and phone information listed on paternity acknowledgement forms in order to contact non-cohabiting and unmarried fathers may be the most effective method of contact for these fathers. Although married fathers should be relatively easy to reach, given that they likely share the address listed on the birth certificate with mothers, many unmarried fathers and mothers sign an acknowledgement of paternity form, which contains contact information that may be utilized. Rates of completed acknowledgement forms do, however, vary by state and information may have to be separately requested through vital records or child support offices.

Reach fathers early, since the highest likelihood of success in reaching new fathers depends on having contact early in the postnatal period.

If reaching fathers in the hospital immediately following the birth of their child is not possible, aim to reach fathers early in the postnatal period, either between 1 and 3 months or 3-6 months after the birth of the infant, as fathers may be more receptive to answering questions at that time. Surveys of both expectant and new fathers suggest that these are the time periods when fathers prefer to be contacted for a study on fatherhood. In our PRAMS for Dads pilot survey, the main PRAMS study already reaches mothers during this time (2-4 months postpartum), so contact at this time promotes a cross-link between the new mother and new father surveys. We therefore recommend similar ability to cross-link by asking mothers and fathers at the same postnatal time.

Bring added value to existing surveillance systems.

PRAMS for Dads bridges directly from the ongoing PRAMS surveillance system for mothers. By integrating and adapting the PRAMS system for fathers, information can be collected on mother-father dyads, forming a family-centered, rather than individual-centered, new parenthood surveillance research project. Further, PRAMS for Dads benefits from a stream-lined approach to data collection, as no additional institutional data has to be collected beyond the birth certificate data already collected as part of PRAMS. Contacting fathers using the MAG approach also benefits from lowered staff requirements, since these mothers are already being contacted to complete the PRAMS survey; pilot data may confirm this. Researchers should evaluate whether complete development of a new system is necessary for fathers, or if they can similarly work in parallel to an already existing surveillance system.

This innovative line of research, while nascent, allows the voices of fathers to be heard in the public health arena. Through full integration of fathers in the formative research of this work, the data collected can inform programs and efforts to prepare men for the transition to fatherhood in such a way to optimize their health and that of 
their partners and children. Further, this approach can be used as a tool to monitor public health issues across the country and provide state, regional, and national level data on fathers and families before, during, and after the birth of a new baby. Ultimately, a more comprehensive understanding of perinatal public health within the context of contemporary families may lead to improved health and wellbeing of fathers, mothers, and infants.

\section{References}

Balluz L, Easton A, Garcia D, Garvin W, Kambon M, MacDonald G, Ramsey F, Ussery-Hall A, Vigeant J (2008) Prevalence of selected risk behaviors and chronic diseases-behavioral risk factor surveillance system (BRFSS), 39 steps communities, United States, 2005. MMWR Surveil Summ 57(11):1-20. https://www.cdc.gov/mmwr/preview/mmwrhtml/ss5711a1.htm

Bianchi SM, Robinson JP, Milke MA (2006) The changing rhythms of American family life. Russell Sage Foundation, New York

Burwick A, Bellotti J, Nagatoshi C (2004) Paths to father involvement: the early head start fatherhood demonstration in its third year. Final report. US Department of Health and Human Services, Head Start Bureau, Washington, DC

Cabrera NJ, Volling BL, Barr R (2018) Fathers are parents, too! Widening the lens on parenting for children's development. Child Dev Perspect 12(3):152-157

Carlson MJ, McLanahan SS (2010) Fathers in fragile families. In: Lamb ME (ed) The role of the father in child development, vol 5. Wiley, New York, pp 241-269

Centers for Disease Control and Prevention (2016) Mother's worksheet for child's birth certificate. https://www.cdc.gov/nchs/data/dvs/moms-worksheet-2016.pdf

Colley BJG, Johnson CH, Morrow B, Gaffield ME, Ahluwalia I (1999) Prevalence of selected maternal and infant characteristics, Pregnancy Risk Assessment Monitoring System (PRAMS). MMWR CDC Surveil Summ 48(5):1-37

Davis NR, Davis MM, Freed GL, Clark SJ (2011) Fathers' depression related to positive and negative parenting behaviors with 1-year-old children. Pediatrics 127(4):612-618

Frey KA, Navarro SM, Kotelchuck M, Michael CL (2008) The clinical content of preconception care: preconception care for men. Am J Obstet Gynecol 199(6):S389-S395

Garfield CF, Duncan G, Gutina A, Rutsohn J, McDade TW, Adam EK, Coley RL, Lindsay ChaseLansdale P (2016) Longitudinal study of body mass index in young males and the transition to fatherhood. Am J Mens Health 10(6):NP158-NP167

Garfield CF, Simon CD, Harrison L, Besera G, Kapaya M, Pazol K, Boulet S, Grigorescu V, Barfield W, Lee W (2018) Pregnancy risk assessment monitoring system for dads: public health surveillance of new fathers in the perinatal period. Am J Public Health 108(10):1314-1315

Groves RM, Mosher WD, Lepkowski JM, Kirgis NG (2009) Planning and development of the continuous National Survey of Family Growth. Vital Health Stat 1 48:1-64

Hirai AH, Kortsmit K, Kaplan L, Reiney E, Lee W, Parks SE, Perkins M, Koso-Thomas M, D'Angelo DV, Shapiro-Mendoza CK (2019) Prevalence and factors associated with safe infant sleep practices. Pediatrics 144(5):e20191286. https://doi.org/10.1542/peds.2019-1286

Hunter T, Cattelona G (2014) Breastfeeding initiation and duration in first-time mothers: exploring the impact of father involvement in the early post-partum period. Health Promot Perspect 4 (2):132-136. https://doi.org/10.5681/hpp.2014.017

Marcell AV, Gibbs SE, Choiriyyah I, Sonenstein FL, Astone NM, Pleck JH, Dariotis JK (2016) National needs of family planning among US men aged 15 to 44 years. Am J Public Health 106 (4):733-739

Martin JA, Hamilton BE, Osterman MJK (2019) Births in the United States, 2018. NCHS Data Brief 346:1-8 
Osborne C, Dillon D (2014) Dads on the dotted line: a look at the in-hospital paternity establishment process. J Appl Res Child 5(2):10

Parker K, Wang W (2013) Modern parenthood: roles of moms and dads converge as they balance work and family. Pew Research Center, Washington, DC

Patel MX, Doku V, Tennakoon L (2003) Challenges in recruitment of research participants. Adv Psychiatr Treat 9(3):229-238

Planalp EM, Braungart-Rieker JM (2016) Determinants of father involvement with young children: evidence from the early childhood longitudinal study-birth cohort. J Fam Psychol 30(1):135

Ramchandani P, Stein A, Evans J, O'Connor TG, ALSPAC Study Team (2005) Paternal depression in the postnatal period and child development: a prospective population study. Lancet 365 (9478):2201-2205

Robbins C, Boulet SL, Morgan I, D’Angelo DV, Zapata LB, Morrow B, Sharma A, Kroelinger CD (2018) Disparities in preconception health indicators - behavioral risk factor surveillance system, 2013-2015, and pregnancy risk assessment monitoring system, 2013-2014. MMWR CDC Surveill Summ 67(1):1-16

Sarkadi A, Kristiansson R, Oberklaid F, Bremberg S (2008) Fathers' involvement and children's developmental outcomes: a systematic review of longitudinal studies. Acta Paediatr 97 (2): $153-158$

Schiller JS, Lucas JW, Peregoy JA (2012) Summary health statistics for US adults: national health interview survey, 2011. Vital Health Stat Ser 10 (256) 1-218

Shulman HB, D'Angelo DV, Harrison L, Smith RA, Lee W (2018) The pregnancy risk assessment monitoring system (PRAMS): overview of design and methodology. Am J Public Health 108 (10):1305-1313

Suellentrop K, Morrow B, Williams L, D'Angelo D, Centers for Disease Control and Prevention (CDC) (2006) Monitoring progress toward achieving maternal and infant healthy people 2010 objectives-19 states, pregnancy risk assessment monitoring system (PRAMS), 2000-2003. MMWR CDC Surveill Summ 55(9):1-11

Teitler JO (2001) Father involvement, child health and maternal health behavior. Child Youth Serv Rev 23(4-5):403-425

US Department of Health and Human Services (2019) Health resources and services administration national performance measures. https://grants6.tvisdata.hrsa.gov/PrioritiesAndMeasures/ NationalPerformanceMeasures. Accessed 14 Nov 2019

Yargawa J, Leonardi-Bee J (2015) Male involvement and maternal health outcomes: systematic review and meta-analysis. J Epidemiol Community Health 69:604-612

Yogman M, Garfield CF, Committee on Psychosocial Aspects of Child and Family Health (2016) Fathers' roles in the care and development of their children: the role of pediatricians. Pediatrics 138(1):e20161128

Open Access This chapter is licensed under the terms of the Creative Commons Attribution 4.0 International License (http://creativecommons.org/licenses/by/4.0/), which permits use, sharing, adaptation, distribution and reproduction in any medium or format, as long as you give appropriate credit to the original author(s) and the source, provide a link to the Creative Commons license and indicate if changes were made.

The images or other third party material in this chapter are included in the chapter's Creative Commons license, unless indicated otherwise in a credit line to the material. If material is not included in the chapter's Creative Commons license and your intended use is not permitted by statutory regulation or exceeds the permitted use, you will need to obtain permission directly from the copyright holder.

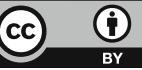

